\title{
Scimitar syndrome with atrial fibrillation: Repair in an adult
}

\author{
Nicholas S. Clarke, MD, Raghav Murthy, MD, and Kristine J. Guleserian, MD, Dallas, Tex
}

\footnotetext{
From the Division of Pediatric Cardiothoracic Surgery, University of Texas Southwestern Medical Center and Children's Medical Center, Dallas, Tex.

Disclosures: Authors have nothing to disclose with regard to commercial support.

Received for publication March 24, 2016; revisions received May 31, 2016; accepted for publication June 5, 2016; available ahead of print July 1, 2016

Address for reprints: Nicholas S. Clarke, MD, UT-Southwestern Medical School, 5323 Harry Hines Blvd, Dallas, TX 75390-9159 (E-mail: Nicholas.Clarke@UTSouthwestern.edu).

J Thorac Cardiovasc Surg 2016;152:e105-7

0022-5223/\$0.00

Published by Elsevier Inc. on behalf of The American Association for Thoracic Surgery

http://dx.doi.org/10.1016/j.jtcvs.2016.06.002
}

Scimitar syndrome consists of a partial anomalous pulmonary venous drainage of the right lung, right lung hypoplasia, dextroposition of the heart, and anomalous systemic arterial supply from the aorta or one of its branches to the right lung. ${ }^{1,2}$ There are both infantile and adult groups. ${ }^{2}$ Scimitar syndrome, like other congenital heart diseases, is commonly associated with atrial tachyarrhythmias as a consequence of atrial dilatation and areas of scar from previous surgical procedures. There is scant literature describing catheter ablation or the Cox maze procedure for arrhythmias related to anomalous pulmonary venous return.

\section{CLINICAL SUMMARY}

A 58-year-old woman with a history of scimitar syndrome was referred to us for surgical repair. At 24 years of age, she received a diagnosis of an atrial septal defect and underwent surgical closure at an outside hospital. Atrial fibrillation was diagnosed in 2008 and managed medically with dofetilide until 2013. In September 2013, the patient was admitted to an outside hospital for congestive heart failure and tachyarrhythmias. On discharge, she underwent an extensive workup including magnetic resonance imaging (Figure 1) and received a diagnosis of scimitar syndrome. She underwent a stress test and cardiac catheterization, which showed no coronary artery disease. Transthoracic echocardiography showed severely dilated right atrium and ventricle, moderate tricuspid regurgitation, mildly dilated left atrium, preserved right ventricular systolic function, and normal left ventricular systolic function with a left ventricular ejection fraction of 55\%. In December 2013, the patient underwent repair of her scimitar syndrome as well as a biatrial Cox maze procedure (Figure 2, A). During the operation, she had markedly dilated right atrium and right ventricle, pulmonary venous drainage from the entire right lung to the inferior vena cava at the level of the diaphragm, and a massively enlarged inferior vena cava. The patient was placed on cardiopulmonary bypass, and the scimitar vein was mobilized and transected from its connection to the inferior vena cava. The scimitar vein anastomosis was her follow-up visits.

\section{DISCUSSION}

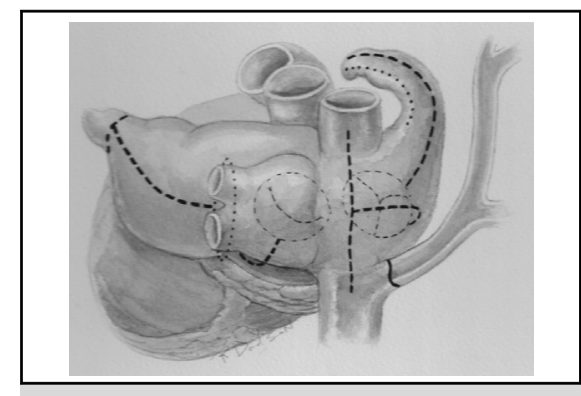

Lesion set for the Cox maze procedure in a patient with scimitar syndrome.

\section{Central Message}

There is scant literature describing repair of an arrhythmia related to anomalous pulmonary venous return. Here we present repair in a 58year-old woman with scimitar syndrome and atrial fibrillation.

See Editorial Commentary page e107.

made to the right atrial free wall, and a 1-mm thick polytetrafluoroethylene (GORE-TEX; W. L. Gore and Associates, Newark, Del) patch was then used to baffle the scimitar vein across the created atrial septal defect (Figure 2, $C$ ) and close the atrial septal defect. The radiofrequency clamp was used to perform the standard right-sided lesion set. The suture line of the scimitar vein to the atrium constituted the pulmonary vein isolation on the right side. The cryoprobe was used to perform the remainder of the box lesions and left pulmonary vein isolation. The patient had an uneventful hospital course but had development of postoperative atrial fibrillation, which resolved with medical management. She has maintained junctional rhythm of 70 to 80 beats/min in

The Cox maze procedure is a concept, not just an operation. The procedure needs to be tailored to specific anatomic variants and congenital heart disease. The standard lesion set described for the Cox maze 4 operation holds good for the anatomically normal heart. There are no descriptions of this surgery being performed on patients with scimitar syndrome in the English language literature. The lesion set needs to be modified in the setting of congenital heart disease. Suture lines are very effective barriers to the propagation of atrial arrhythmia wave front. This is true only when they are placed in specific anatomic locations. The anastomosis of the scimitar vein to the atrial free wall 


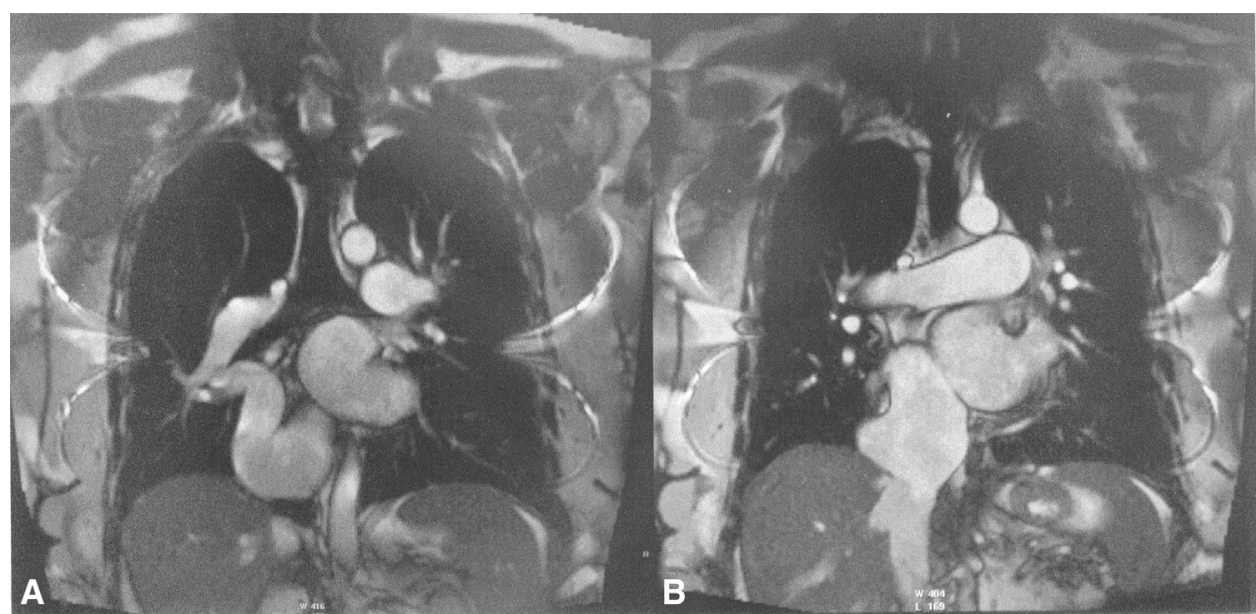

FIGURE 1. A, Course of the scimitar vein. B, Attachment of the scimitar vein to the inferior vena cava just above the diaphragm.

provides elective pulmonary vein isolation. This can be confirmed by exit and entrance block. One of the contributors to atrial tachyarrhythmias in congenital heart disease is the atrial scarring from previous heart surgery. The location of the scar lines and atrial dilation secondary to the underlying disease state contribute to this.
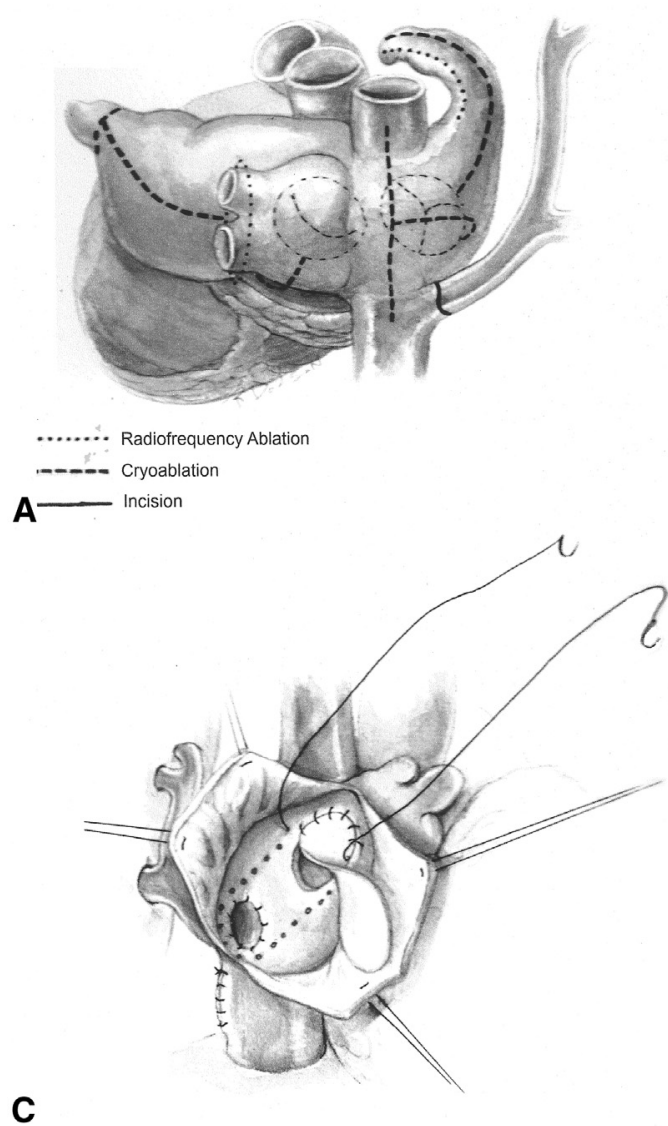

Very little information exists with regard to the effectiveness of the Cox maze procedure on structurally abnormal hearts in the setting of congenital heart disease. Gutierrez and colleagues ${ }^{5}$ described 24 patients with congenital heart disease who underwent the Cox maze 3 procedure at the time of concomitant cardiac surgery. Twenty-one patients survived to
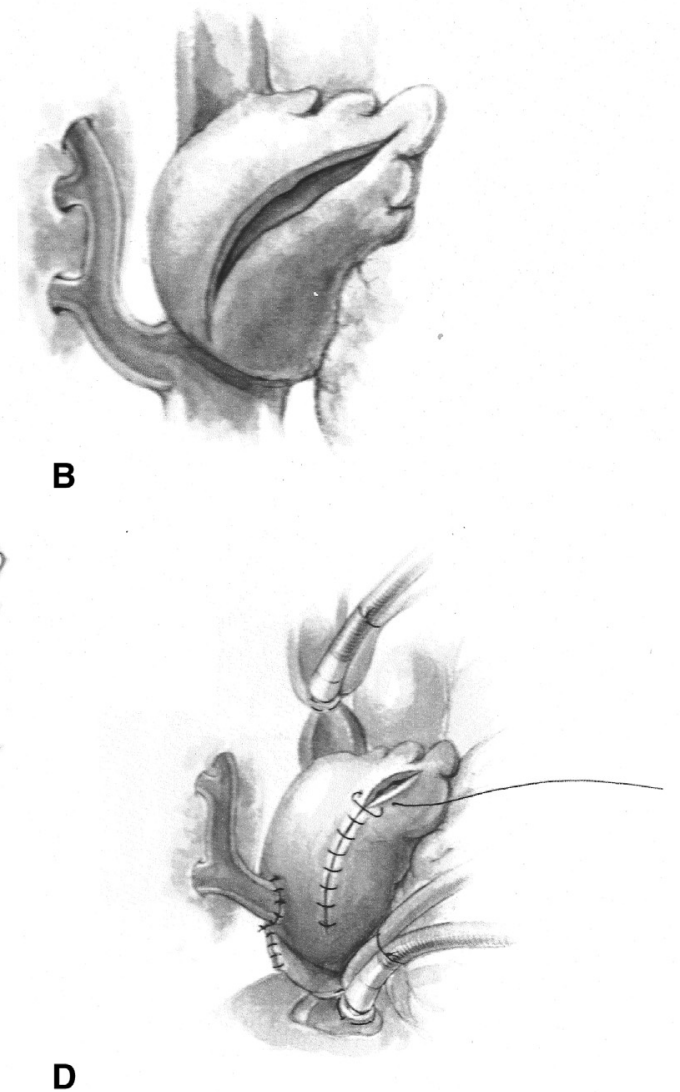

FIGURE 2. A, Cox maze lesion set in a patient with scimitar syndrome. B, Incision parallel to the atrioventricular groove. C, Scimitar vein is baffled to the left atrium. D, Completed repair. 
discharge. Of the $21,14(74 \%)$ were arrhythmia free at a mean follow-up of 2.8 years. Only 3 of the patient included in the study had anomalous pulmonary venous return. The European Congenital Heart Surgeons Association study group ${ }^{1}$ reviewed 68 patients who underwent surgery for scimitar syndrome, and in their report only 1 patient underwent a Cox maze operation. The report unfortunately does not describe the details of the surgery or the effectiveness of the procedure.

\section{CONCLUSIONS}

The Cox maze 4 lesion set can be performed safely and effectively in patients with Scimitar syndrome. The lesion set needs to be modified in the setting of anatomic abnormalities.

\section{References}

1. Vida VL, Padalino MA, Boccuzzo G, Tarja E, Berggren H, Carrel T, et al. Scimitar syndrome: a European Congenital Heart Surgeons Association (ECHSA) multicentric study. Circulation. 2010;122:1159-66.

2. Brink J, Yong MS, D’Udekem Y, Weintraub RG, Brizard CP, Konstantinov IE Surgery for scimitar syndrome: the Melbourne experience. Interact Cardiovasc Thorac Surg. 2015;20:31-4.

3. Kirubakaran S, Rajani R, Linton N, Kiesewetter C, Anderson D, O'Neill M. Catheter ablation for persistent atrial fibrillation in a patient with previous repair of total anomalous pulmonary venous connection. Circ Arrhythm Electrophysiol. 2013;6: e54-5.

4. Fukamizu S, Sakurada H, Nishizaki M, Hiraoka M. Catheter ablation in a patient with partial anomalous pulmonary venous return and atrial fibrillation. Heart Rhythm. 2012;9:1002-3.

5. Gutierrez SD, Earing MG, Singh AK, Tweddell JS, Bartz PJ. Atrial tachyarrhythmias and the Cox-maze procedure in congenital heart disease. Congenit Heart Dis. 2013;8:434-9.

\title{
EDITORIAL COMMENTARY
}

\section{The bad guy, good guy scenario with a scimitar sword: A case to learn from}

\author{
Hani K. Najm, MD, MSc
}

From the Department of Pediatric and Congenital Heart Surgery, Cleveland Clinic, Cleveland, Ohio. Disclosures: Author has nothing to disclose with regard to commercial support.

Received for publication July 14, 2016; accepted for publication July 18, 2016; available ahead of print Aug 13, 2016.

Address for reprints: Hani K. Najm, MD, MSc, Department of Pediatric and Congenital Heart Surgery, Cleveland Clinic, 9500 Euclid Ave, M41, Cleveland, OH 44195 (E-mail: najmh@ccf.org).

J Thorac Cardiovasc Surg 2016;152:e107-8 0022-5223/\$0.00

Copyright (C) 2016 by The American Association for Thoracic Surgery http://dx.doi.org/10.1016/j.jtcvs.2016.07.030

Today it would not be acceptable to close an atrial septal defect and leave the anomalous scimitar vein draining to the inferior vena cava (IVC). The case presented by Clarke and colleagues ${ }^{1}$ in this issue of the Journal highlights how the care of patients with congenital cardiac defects has dramatically improved. Clearly, in the early 1980s when the first surgery was done for this patient, transesophageal echocardiography, magnetic resonance imaging, and computed tomographic scans were not routine in refining the diagnosis. In contrast, the use of one of these modalities is now essential in delineating anatomic pathophysiology.

A surgeon closing an atrial septal defect must go through the basics to check that the diagnosis is accurate. An oversized IVC should raise a flag of an abnormal drainage, and certainly failure of resolution of volume overload should raise another. We assume that this case also demonstrated the other features of scimitar

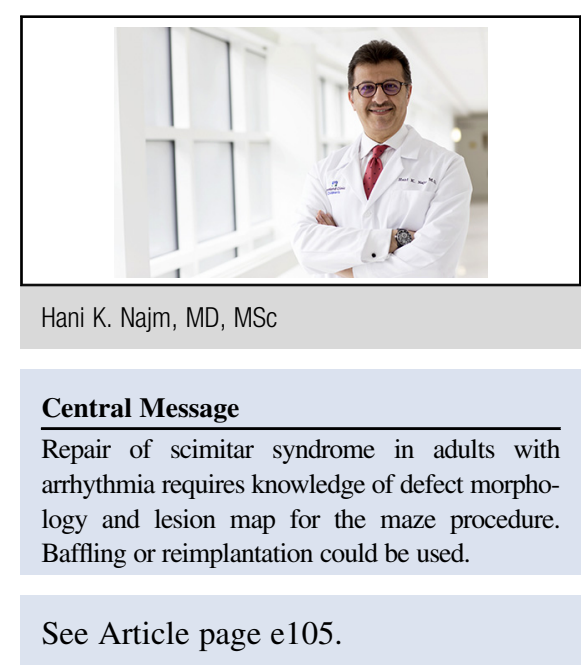

syndrome-namely, the arterial supply of the right lung, the dextroposition, the hypoplasia of the right lung, pulmonary hypertension, and other associated lesions such as horseshoe lungs - although the specific findings were not detailed in the report. Most of these features are present in the infantile from of the syndrome and may not be present in the milder adult form.

Surgical techniques have varied through the years, with outcomes varying with the type. The techniques ranged from reimplantation to baffling, with numerous 